\title{
Percursos Formativos a caminho da descolonização didática: quais enfrentamentos no Ensino das Ciências na Educação Básica?
}

\author{
Rosiléia Santana da Silva' ${ }^{\text {(iD }}$ \\ Univeversidade Federal da Bahia \\ Luiz Marcio Santos Farias 2 iD \\ Univeversidade Federal da Bahia

\section{Dossiê | Dossier | Dosier \\ RESUMO} \\ DOI do artigo: 10.22481/odeere.v6i2.9805
}

Neste artigo buscamos apresentar um relato de experiência vivenciada numa formação continuada, em 2019, entre docentes de história, biologia, química, física e matemática da Rede de Ensino do Estado da Bahia. A formação é parte da tese de doutorado, desenvolvida no Programa de Pós-Graduação em Ensino, Filosofia e História das Ciências da Universidade Federal da Bahia (PPGEFHC-UFBA), que tem como sentido potencializar a descolonização de saberes científicos e do fazer didático no ensino das ciências (humanas, da natureza e exatas) da educação básica. Mesmo diante da vanguarda dos movimentos sociais negro-pindorâmico e das determinações da Lei-Base para a Educação de 2003, reforçado em 2008, ainda há enfrentamentos frente aos entraves e desafios no fazer didático no chão da sala de aula. Nesse sentido, as influências de um modelo praxeológico de referência (MPR) pautado na descolonização dos saberes foi repertório no processo formativo para a integração das abordagens etnicorraciais no ensino enquanto modelos de referência a serem ensinados.

Palavras-chave: Educação das Relações Etnicorraciais; Ensino das Ciências (humana, da natureza e exatas), Modelos Praxeológicos de Referências, Descolonização Didática.

Formative Paths On The Way To Didactic Decolonization: what confrontations in science teaching in Basic Education?

ABSTRACT

In this article we seek to present a report of an experience lived in a continued training, in 2019, among teachers of history, biology, chemistry, physics and mathematics of the Education Network of the State of Bahia. The training is part of the doctoral thesis, developed in the Graduate Program in Teaching, Philosophy and History of Science at the Federal University of Bahia (PPGEFHC-UFBA), which aims to potentiate the decolonization of scientific knowledge and the didactic process in the teaching of sciences (human, natural and exact) in basic education. Even in the face of the vanguard of Afro-Brazilian social movements and of the determinations of the 2003 Basic Law for Education, reinforced in 2008, there are still confrontations in the face of obstacles and challenges in the didactic process on the classroom floor. In this sense, the influences of a praxeological model of reference (MER) based on the decolonization of knowledge was a repertoire in the formative process for the integration of ethnoracial approaches in teaching as reference models to be taught.

Keywords: Education of Ethnic-Racial Relations; Teaching of Sciences (human, natural and exact), Praxeological Models of Reference, Didactic Decolonization.

Submetido em: 20/10/2021 | Aceito em: 24/11/2021

1 Professora na Rede de Educação do Município de Cairu (BA), sócia da ANPUH-BA, da ABPN - BR e membra do Núcleo Interdisciplinar de Pesquisa, Ensino e Didática das Ciências e Tecnologia (UFBA). Possuo Licenciatura e Bacharelado em História pela Universidade Católica do Salvador, com especialização em História Social e da Cultura Afrobrasileira e Indígena (Faculdade da Cidade). Mestra e Doutoranda em Ensino, Filosofia e História das Ciências pela Faculdade de Educação (UFBA/UEFS). Nessa mesma Faculdade, fui professora substituta de Didática e Práxis Pedagógica de História I/II e Metodologia do Ensino de História e, na UNEB atuei como tutora presencial nos cursos de Pedagogia e História. E-mail: leiasansilva@gmail.com

2 Professor do Instituto de Humanidades, Artes e Ciências Prof. Milton Santos (IHAC), Coordenador do Bacharelado Interdisciplinar em Ciência e Tecnologia-IHAC, da Universidade Federal da BahiaUFBA, da Faculdade de Educação da UFBA e do Programa de Pós-Graduação em Ensino, Filosofia e História das Ciências da UFBA/UEFS, do qual foi coordenador de 2014 a 2016 e de 2016 a 2018. Graduado em Matemática (UFBA/UCSAL), Pós-graduado em Didática e Metodologia do Ensino Superior (EEAB), Mestre (UJF-França) e Doutor (UM2-França) em Didática das Ciências e Matemática. E-mail: Imsfarias@ufba.br 


\section{INTRODUÇÃO}

O presente relato tem como objetivo apresentar partes das vivências ocorrida numa formação continuada cujo propósito foi integrar e potencializar saberes africanos e afro-brasileiros às construções didáticas de professoras da educação básica da rede de ensino estadual da Bahia. Essas articulações estão vinculadas às demandas e determinações da Lei de Diretrizes e Bases da Educação (9394/96) a partir da sua alteração, em 2003, através da lei 10.639 e reforçada em 2008 conforme a lei 11.645.

A lei 10639/03, junta às Diretrizes Curriculares Nacionais para a Educação das Relações Etnicorraciais e para o ensino de História(s) ${ }^{3}$ e Culturas(s) Afro-Brasileira e Africana, vem, ao longo dos seus dezoito anos, buscando promover rupturas coloniais que historicamente destitui as existências, cosmologias, epistemologias, ciências, tecnologias, saberes e fazeres não-europeus na educação formal. No entanto, mesmo com a vanguarda das determinações legais e de todo protagonismo e produções, há décadas, dos movimentos sociais negropindorâmico, a agência africana, afro-brasileira e pindorâmica ainda não são consideradas, efetivamente, nas articulações e institucionalizações de saberes.

Apesar do vasto repertório das pesquisas e debates, tanto no campo comunitário quanto no acadêmico, nos campos escolares, as transposições de saberes e as propostas didáticas continuam singularizadas pelos projetos pedagógicos, nas datas comemorativas e entre à "solitude de docentes descoloniais 4 , incorrendo nos obstáculos e vazio didático5 (FARIAS, 2010).

Apesar da Lei 10639/03 determinar que o ensino das Histórias e Culturas Africanas e Afro-brasileiras seja para todas as áreas de conhecimento, professores, principalmente, das Ciências da Natureza e Matemática revelam não saber como integrar contribuições afro-referenciadas aos conteúdos institucionalizados como oficiais dos seus currículos. O astrofísico Alves-Brito e demais autoras (2018)

\footnotetext{
${ }_{3}$ No plural, em respeito à diversidade etnicocultural existente em um continente constituído por 54 países.

${ }_{4}^{4}$ Aquela/e que potencializa abordagens descoloniais todo o ano letivo nos seus conteúdos programático e não se reduz à momentos específicos. No entanto, a depender da unidade escolar e redes de ensino, torna-se a/o/e profissional estigmatizado por romper com os currículos e projetos de tradição cânone.

5Segundo Farias (2010), é caracterizado pelas evidentes restrições nos conteúdos que desencadeiam na ausência de sugestões para execução do objeto/conteúdo, já que a(o/e) docente não encontra ecologia (espaço e funcionalidade) que possibilite alicerçar e construir nas suas práticas.
} 
observam que,

com raras exceções, os poucos materiais disponíveis sobre os temas étnicoraciais em ciências exatas, [...] estão restritos a artigos científicos técnicos da área que (i) ou não chegam ao conhecimento dos professores da rede básica de ensino (ii) ou são incompreendidos pelos mesmos, dificultando a criação de materiais adaptáveis à realidade dos alunos e do Ensino Básico (Alves-Brito; Bootz \& Massoni, 2018, p.920).

Essas observações entrecruzam com as dificuldades e desafios revelados pelo corpo docente que, uníssono, declara não saber o que ensinar, como ensinar, quais referências teórico-historiográficas se fundamentar e quais ferramentas didáticas se estruturar para uma construção que supere o colonialismo epistêmico e curricular. Em 2017, Santana, Rebelo-Pinto e Farias, apresentaram uma amostra de com 52 docentes ${ }^{6}$ da educação básica entrevistadas (os/es) onde, dessas, 70\% revelaram não contemplar os propositivos determinados pela lei nas suas atividades.

Mas, por que ainda não são implementadas, efetivamente, ao longo do ano letivo, conteúdos que contemplem as contribuições etnicorraciais? Quais as entraves e enfrentamentos? Quais instrumentos possuímos para contemplar modelos de referências descoloniais? Esses questionamentos são latentes desde 2015, junta ao Núcleo Interdisciplinar de Pesquisa, Ensino, Didática das Ciências, Matemática e Tecnologias (NIPEDICMT) da UFBA.

Desde então, temos desenvolvido investigações no campo da Didática das Ciências7 integrando-o às abordagens descoloniais afro-referenciadas, com o objetivo, sobretudo, de fomentar dispositivos didáticos que contribuam no combate ao racismo epistêmico, científico e didático nos chãos da sala de aula.

Também por isso, e de respostas aos nossos questionamentos, promovemos, em 2019, o curso formativo8 de co-participar-ação, empenhado em promover modelos de referências didáticas descolonizadas nos ensinos das ciências. Em

\footnotetext{
${ }^{6}$ Apesar do estado baiano compor uma população majoritariamente negra (preta e parda, de acordo ao IBGE: censo demográfico),

7 Campo de investigações que visa melhorar as condições de aprendizagem dos alunos e renovar as metodologias do ensino científico (científico aqui, abrange-se à todas as ciências (humanas, exatas, das linguagens, dentre outras, se assim houver). Ver mais: Astolfi et al. (1990), Chevallard (1985) e Cachapuz(1995).

8 Formação Interdisciplinar em História, Matemática e Ciências Naturais: A Teoria Antropológica do Didático para uma Integração das Contribuições Africanas e Povos das Diásporas às Práticas de Professores.
} 
análise a priori, no percurso, inquirimos às participantes 9 sobre as motivações que levaram à realização do curso. Diante de algumas das respostas, um professor de Física afirmou que seu interesse perpassava por "trabalhar", "compreender", "aperfeiçoar" e "desenvolver" conteúdos etnicorraciais no Ensino de Física. Declarou:

[tenho] Interesse em trabalhar os conteúdos de forma prática para melhorar a compreensão dos assuntos através de uma abordagem mais próxima da realidade do aluno. Buscar um aperfeiçoamento para o desenvolvimento pessoal e profissional na minha carreira docente. Professor de Física da Rede Estadual da Bahia, 2019.

Uma professora de Biologia, sobre a mesma pergunta, respondeu que seu interesse perpassava por "acreditar", "valorizar", "atualizar", "transformar" e "desenvolver". Aponta:

Em primeiro lugar, acredito que a interdisciplinaridade é uma das características da educação que precisa ser mais explorada pelos professores. Em segundo lugar, trabalho em escolas públicas com jovens que não são ensinados a valorizar suas raízes. Acredito que a educação pode e deve ser transformadora e que devemos nos atualizar para vencermos as barreiras do distanciamento daquilo que é ensinado nas escolas com aquilo que é vivenciado no dia a dia (professora de Biologia da Rede Estadual da Bahia).

As respostas acima, e das demais pessoas participantes, puderam nos revelar que, diante dos esvaziamentos de abordagens etnicorraciais na formação inicial, assim como o hiato entre o teórico e prático, há a necessidade de aprofundamentos de estudos, formações continuadas e aquisição de ferramentas didáticas para promoção efetiva daquilo que as diretrizes curriculares sugerem.

O professor de física aponta que tem interesse em propor abordagens sobre alteridade nas ciências, que ultrapassem o que é instituído como tradicional ao ensino de Física. Para além disso, a sua motivação revela a necessidade do seu letramento racial e antirracista para seu "desenvolvimento pessoal", assim como, efetivar o exercício de práticas antirracistas e descolonizadoras com o seu "aperfeiçoamento profissional". A professora de biologia, por sua vez, reporta seus anseios em reconstruir propostas didático-pedagógicas transformadoras que ressignifique e reconheça as identidades ancestrais africanas, vivas, nos chãos das

9 O curso foi realizado entre outubro-novembro de 2019, através do Programa de Apoio ao ProCEAO (UFBA), em parceria com o Núcleo Territorial de Educação -NTE 19 (Feira de Santana Bahia), onde tivemos, em média, 60 professores inscritos. 
salas de aula a partir de uma relação dialógica e horizontalizada entre as diferentes áreas de conhecimento.

Essas vozes denunciam a distância e esvaziamento do ensino e das in(visibilidades) na história das ciências (Alves-Brito et al., 2020) na educação científica. Os corpos "não-brancos", principalmente negro e pindorâmico, são legados ao apagamento e subalternização nas referências teóricas, pedagógicas e epistêmicas da Educação em Ciências (principalmente, das Exatas). As referências são sempre baseadas num complexo em que as pessoas brancas (europeia) são tratadas como condição humana normativa e universal, como argumentam Rosa, Alves-Brito e Pinheiro (2020, p.1445).

Prosseguimos, portanto, na urgência de potencializar a descolonização dos saberes e da didática enquanto mais um dos instrumentos de combate às múltiplas violências perpetradas pelo colonialismo e reverberadas pela lógica da colonialidade nos chãos das salas de aulas. Apesar dos 18 anos da lei 10.639/2003 e dos 20 anos da Conferência de Durban'10 (2001), a ausência completa do cumprimento da Lei ainda é potencial tanto na Educação Básica quanto na Educação Superior.

Neste sentido, parafraseando Rufino (2020, p. 08), é nossa responsabilidade assumir a emergência e a credibilização de outros saberes, diretamente comprometidos, agora, com o reposicionamento histórico daqueles que os praticam. Tão por isso, que busquemos firmar respostas que combatam a baixa estima imposta, sobretudo, porque, a problemática do conhecimento é fundamentalmente etnicorracial (Rufino, 2020).

\section{METODOLOGIA: OUTROS SABERES. OUTRAS POSSIBILIDADES. OS FAZERES SÃO POSSÍVEIS A PARTIR DAS ENCRUZILHADAS}

O percurso metodológico que seguimos foram articulados e possibilitados considerando, de início, o sentido dos cruzos, da encruzilhada, ao propor

\footnotetext{
10 Foi um Encontro Mundial de iniciativa da Organização das Nações Unidas, na África do Sul, com o objetivo de "pactuar um programa de ação direcionado ao combate ao racismo, à Discriminação Racial, Xenofobia e Intolerância Correlata. Representando assim um marco fundamenta na percepção e nas práticas de violência histórico e, no caso específico do Brasil, foi implementado instrumentos legais basilares voltadas ao combate, promoções efetivas da reparação. A exemplo das Leis 10639/03, 11645/08, 10.678/03, 12.288/2010 e 12.711/12.
} 
abordagens entre a Teoria Antropológica do Didático de Chevallard (1991) e Perspectivas Afro-referenciadas. Para Rufino (2020) o sentido de encruzilhada emerge como disponibilidades para novos rumos, novos fazeres, novos campos de possibilidades na transgressão da escassez, das ausências e dos silenciamentos.

À luz desse sentido, o curso foi estruturado'll sob metodologia da pesquisaação ${ }^{12}$ de forma participativa e colaborativa entre docentes de História, Matemática, Química, Física e Biologia. Conforme o recurso de um Percurso de Estudo e Pesquisa (Chevallard, 2009, dinamizamos gestos didáticos através de perguntas a serem respondidas e problemas a serem resolvidos entre as professoras e professores. Por vias dessa estrutura, o repertório metodológico-didático fundamentou-se no questionamento do mundo (CHEVALLARD, 2012), atravessados pela ruptura das hierarquias exercidas entre os saberes institucionalizados para $\circ$ ensino escolar de história, ciências da natureza e matemática do $1^{\circ}$ ano do ensino médio.

O aporte teórico da Antropologia do Didático (Chevallard, 1991) é uma peça importante na formação de professoras(es) porque, para além de outras instrumentalizações, a teoria nos proporciona estudar a prática sociocultural ao lidar com qualquer saber e ao lidar com situações que fazer emergir um saber $r$, seja ele saber matemático, histórico, químico, alimentar, dentre outros. Ter a TAD como nossa fundamentação teórico-metodológica, portanto, no processo formativo nos possibilitou perceber as condições e restrições curriculares e didáticas para que a docente pudesse cruzar saberes africanos e afro-brasileiros nas atividades propostas

A partir desse cenário, dividimos as construções em três módulos:

No módulo 1, intitulado Modelos abertos de aprendizagem: aprendizagem por investigação, baseada em problemas e Percursos de Estudo e Pesquisa (PEP), foi abordado sobre o PEP enquanto um modelo aberto de investigação numa pesquisa ou num estudo em sala de aula. Através de solicitação de atividades as cursistas puderam acessar conhecimentos teóricos da TAD com o fazer, isto é, com a prática, onde a partir de temas voltados referente ao ensino da História e Cultura

\footnotetext{
11 Foi estruturado na modalidade híbrida, acontecendo $60 \%$ das construções à distância através do AVA Google Classroom e $40 \%$ das construções presencial com elaborações didáticas.

12 A pesquisa ação é um tipo de pesquisa social com base empírica que é concebida e realizada em estreita associação com uma ação ou com a resolução de um problema coletivo e no qual os pesquisadores e os participantes representativos da situação ou do problema estão envolvidos de modo cooperativo ou participativo. (THIOLLENT, 2011, p. 20).
} 
Afro-Brasileira nos seus componentes curriculares, promoveram gestos didáticos através perguntas a serem respondidas numa sala de aula.

Figura 1: Atividades aplicadas no curso

QUESTÃO 1

a) Você como professor (a) ou estudante de licenciatura conhece ou já utilizou algum modelo aprendizagem por investigação, baseada em problemas? Se sua resposta foi sim, liste o (s) que você conhece ou já utilizou.

QUESTÃO 2

Apresente uma síntese de um modelo citado acima, como resposta da questão 1.

QUESTÃO 3

As questões se apresentam de forma interdisciplinar no cotidiano, porém para efeito didático e pedagógico é necessário desdobrá-las em conteúdos dentro de uma dada ciência. A partir disso, liste os conteúdos da sua disciplina em que as questões étnico raciais podem ser abordadas.

QUESTÃO 4

Pensando no modelo citado na resposta à questão 2 ou em um dos modelos apresentados neste módulo, como você desenvolveria um estudo envolvendo a disciplina que leciona abordando as questões étnico raciais? Responda usando um exemplo prático.

Bom trabalho!!

Fonte: NIPEDICMT, 2019.

No módulo 2, intitulado Interculturalidade e multidisciplinaridade; Epistemologias do Sul, Descolonização epistemológica e didática; Relações Ełnicorraciais no ensino das ciências e Matemática, foi proposto um diálogo e tarefas considerando a lógica da Epistemologia do Sul, a fim da Descolonização Epistemológica e Didática. A proposta das Epistemologias do Sul, trazida por Boaventura Santos (1995), advém do reconhecimento de que, para além de todas as formas de repressão que conhecemos, o colonialismo estabeleceu também a repressão através da "dominação epistemológica". Questionar, portanto, a dominação epistemológica nos levar a propor e garantir novas epistemologias seguindo um percurso de/para a descolonização epistemológica e didática. 
Diante das leituras propostas acima, responda:

1. Qual(is) disciplina(s) você leciona?

2. Quais elementos presentes nos textos acima você desconhecia?

3. Diante do revelado, no texto acima, descreva 5 potenciais lacunas na sua área de ensino/formação.

4. Diante dessas lacunas, o que é possível construir e propor nas suas propostas didáticas?

5. Marque a alternativa correta:

A expropriação das histórias dos países africanos por meio da subtração de bens pelos europeus no período colonial indica que:

a. ( ) Existiu algum interesse dos europeus pelos diferentes conhecimentos africano.

b. ( ) Colonos e metropolitanos conviviam harmonicamente com respeito mútuo às culturas diferentes.

c. ( ) Os europeus inicialmente desprezaram o conhecimento e a cultura africana

6. Didaticamente construindo... A partir do textos básico e básico complementar "Uma revisão de Literatura para refletir o Ensino de Ciências, os saberes populares e a Afrocentricidade", liste os conteúdos da sua disciplina, presente no programático do ano letivo, que aborde a educação das relações etnicorraciais.

7. A partir da listagem acima, aponte os aspectos que considera mais relevantes com a sua experiência em sala de aula. Narre o porquê dessa relevância.

Bom trabalho!!

Fonte: NIPEDICMT, 2019.

No módulo 3, intitulado Elaboração de tarefas para web; é possível implementar um PEP com ferramenta web? e construindo seu próprio material curricular: softwares de autoria, foi promovido construções em que as cursistas analisaram relações pessoais com os objetos da sua área do conhecimento e modelizaram tarefas e/ou situações didáticas através do recurso didático Ardora 713.

Figura 3: Atividades aplicadas no curso

13 A título de exemplificação de possíveis caminhos para criação de atividades. $\bigcirc$ Ardora 7, é um exemplo de aplicativo com tal finalidade. Ele foi criado por José Manuel Bouzan Matanza e é totalmente gratuito. Nos auxilia naqueles momentos em que não encontramos no livro aquela tarefa que melhor corresponde ao que deseja realizar com a turma, ou para adaptar e propor situações didáticas bem interessantes. Esse aplicativo nos permite criar atividades, em formato html de uma maneira bem simples, ideal para nós professoras(es). Dentre as atividades que podem ser elaboradas temos: jogos de palavras, atividades com imagens, com sons, de relacionar, completar, classificar, ordenar, selecionar, testes, unidades de medida, esquemas, cálculo, em muitas outras. 


\begin{abstract}
Atividade
Elabore uma sequência didática inspirada no PEP utilizando o conteúdo Origem da Humanidade e da Vida para o 1 Ano EM, intercruzando de forma interdisciplinar. Pense numa questão diretriz do PEP no âmbito das discussões étnico-raciais, de acordo com o módulo 2, o foco deve ser na descolonização de saberes (você já respondeu a algumas questões que podem facilitar a discussão nessa proposta de sequência, em que a invisibilidade de um passado em ciência e tecnologia dos povos africanos e da diáspora é ponto de reflexăo sobre a temática geral do curso. Nessa sequência inspirada no PEP, você pode partir dessa discussão, mas fica livre para pensar a partir das contribuições dos dois módulos anteriores, em outras reflexỏes em torno das relaçốes étnico-raciais e da descolonização dos saberes). Faça isso utilizando ferramentas da web 2.0. Pense como o Ardora pode auxiliar na elaboração desse PEP.
\end{abstract}

Bom trabalho!

Fonte: NIPEDICMT, 2019.

Os trabalhos foram desenvolvidos pela performance do percurso de estudos e pesquisa, nos quais foram realizadas análises a priori, ação importante na investigação didático, e por esse caminho, prognosticar os comportamentos das(os) participantes diante das tarefas iniciais ${ }^{14}$. As abordagens teóricas e conceituais, em meio ao repertório metodológico, buscaram contemplar: a sensibilização aos engessamentos dos currículos, dos instrumentos didáticos e das práticas fomentado pela colonialidade do saber; realização de estudos analíticos e exploratórios através de análises documentais (DCNERE15, BNCC, Livros Didáticos utilizados no ano letivo, Propostas Curriculares da Bahia e Planos de Aula), questionamentos, planejamentos e reconstruções de tarefas numa perspectiva descolonizadora.

Foi diante dessa encruzilhada que a noção de didática das ciências valorizou a ampliação de abordagens etnicorraciais, frente as fronteiras coloniais nos campos dos diferentes conhecimentos, principalmente das ciências extas e da natureza, possibilitando fazeres - do ensino à aprendizagem - diante das condições e restrições (Chevallard, 2009) impostas pela sociedade. Afim de, como anunciou a professora de Biologia, se "atualizar para vencermos as barreiras do distanciamento daquilo que é ensinado nas escolas com aquilo que é vivenciado no dia a dia". Em miúdos, estabelecer uma relação dialógica entre o currículo oficial e o currículo vivo proveniente das experiências individuais, assim como, o

\footnotetext{
14 Figuras 1, 2 e 3.

15 Diretrizes Curriculares Nacionais para a Educação das Relações Étnico-Raciais.
} 
que se propõe executar conforme as suas ferramentas didáticas, considerando as agências negras e pindorâmicas vivas no contexto da comunidade escolar.

Esse movimento espiral, consideramos ser uma das metodologias da Pedagogia da Encruzilhada, de Luiz Rufino (2019), no qual somos convocadas(os) à descolonização das práticas, ou como defende Silva (2017), à descolonização didática. Que, segundo Rufino, para além do conceito, a descolonização é um ato permanente de transformação social na vida comum como um ato revolucionário. Tornando-se, com isso, uma mudança paradigmática e comportamental no campo didático e da didática.

\section{CAMINHOS PARA UMA PRÁTICA DESCOLONIZADORA: ALGUNS MOVIMENTOS DIDÁTICOS}

A promoção das formações continuadas às(aos) docentes é mais uma das estratégias promovidas por intelectuais 16 negra-diaspóricas, no campo da Educação, para a implementação de políticas públicas no enfrentamento e combate ao racismo. É, portanto, o chão da sala de aula, acadêmico e escolar, um espaço fértil na diversidade, demarcado pelos choques afeto-identitário promovendo convergências e divergências, acolhimento e negação, escutas e silenciamentos, visibilidades e invisibilidades pautado na hierarquização geopolítico-social dos saberes, dos poderes (Quijano, 2000), diante das subjetividades.

O racismo para nós, como argumenta Silva (2018, p.45), é também um racismo epistêmico que marca os espaços formais da educação, sobretudo, científica ao potencializar discursos científicos racistas submetendo pessoas do global sul à sub-representação intelectual, nas ciências e nos feitos científicos enquanto sujeitas(os) inteligências.

Considerando depoimentos de docentes sobre não saber como integrar contribuições etnicorraciais aos seus conteúdos, conduzimos os módulos ${ }^{17}$ na base

\footnotetext{
16 A noção, aqui, de intelectual e intelectualidade ultrapassa o sentido acadêmico-formal constitutivo. Mas agrega todas as mestras e mestres, quilombolas, ribeirinhas, líderes religiosas, educadores sociais, líderes comunitárias que, a partir de seus saberes orgânicos (Bispo, 2015), vivências e experiências ancestrais promovem construções efetivas e afetivas em defesa e combate à todas as formas de violências de cunho racial, gênero e classe em territórios brasileiros.

17 O curso promovido em 2019 foi subdividido em três módulo, no entanto, nos atemos a apresentar apenas o módulo II referente aos temas: descolonização, educação das relações etnicorraciais e ensino das ciências (humanas, exatas e da natureza).
} 
de análises e questionamentos ${ }^{18}$ para as construções de tarefas como propostas didáticas. Em busca das respostas sobre como subsidiar de forma teórica e metodológica o trabalho de professores da educação básica interessados na integração de contribuições africanas e afro-brasileiras, introduzimos o vídeo "Mentiras na Educação e na Mídia" de Yosef Ben Jochannan 19(1970) e o texto de Molefi Kete Asante (2010), "Raça na Antiguidade: na verdade, provém da África".

A análise do texto e do vídeo foram acompanhados com perguntas e respostas apresentando as epistemologias hegemônicas, as quais apontaram as condições e restrições nas respectivas áreas de ensino nos espaços escolares. E, apartir desse diagnóstico, (quadro 1) os mesmos buscaram vivenciar e reconstruir propostas pautadas em epistemologias afrocentradas, utilizando as relações etnicorraciais a fim de responder a nossa questão geratriz.

Quadro 1: Perguntas e respostas no processo construtivo

\begin{tabular}{|c|c|c|c|}
\hline & $\begin{array}{l}\text { Q2- Das abordagens } \\
\text { descoloniais, o que } \\
\text { desconhecia na área de } \\
\text { conhecimento? }\end{array}$ & $\begin{array}{l}\text { Q3 - Quais lacunas você } \\
\text { identifica sua área de } \\
\text { conhecimento. }\end{array}$ & Q4 - Diante das lacunas, dê sugestão de propostas didáticas? \\
\hline $\begin{array}{l}\text { Profa A. Santos } \\
\text { (Matemática) }\end{array}$ & $\begin{array}{l}\text { O discurso racista da } \\
\text { professora Mary Lefkowitz. }\end{array}$ & 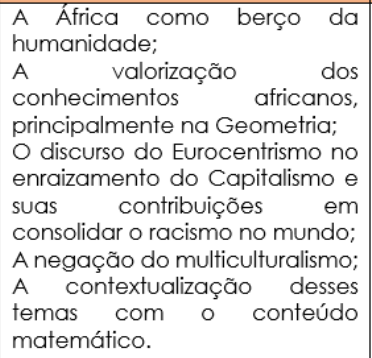 & $\begin{array}{l}\text { Pesquisa de campo, referente às diversidades culturais no município de } \\
\text { Antônio Cardoso (Ba), tendo como foco o Samba de Roda e a } \\
\text { Capoeira. } \\
\text {-Origem; } \\
\text {-História; } \\
\text {-Quantidade de grupos; } \\
\text {-A importância dessas culturas para o município; } \\
\text { As contribuições culturais na vida dos jovens que participam desses } \\
\text { grupos. }\end{array}$ \\
\hline $\begin{array}{l}\text { A.Cerqueira } \\
\text { (História } \\
\text { Sociologia) }\end{array}$ & $\begin{array}{l}\text { O conceito } \\
\text { Afrocentricidade e suas } \\
\text { características. } \\
\text { A origem kemética dos } \\
\text { deuses gregos. } \\
\text { Que os gregos foram alunos } \\
\text { dos egípcios. } \\
\text { O silenciamento organizado } \\
\text { da historiografia e bibliografia } \\
\text { oficiais sobre a contribuição } \\
\text { da civilização kemética para } \\
\text { as ciências ocidentais. }\end{array}$ & $\begin{array}{l}\text { O conceito de Afrocentricidade } \\
\text { e suas características; } \\
\text { A influência da religião } \\
\text { kemética na grega; } \\
\text { A ideia de mitologia racial; } \\
\text { O desconhecimento de obras } \\
\text { de autores africanos, que } \\
\text { tragam o ponto de vista } \\
\text { daqueles sobre o continente, } \\
\text { seus problemas e mazelas } \\
\text { econômicas, políticas e sociais; } \\
\text { A dívida da civilização grega } \\
\text { para com a África. }\end{array}$ & $\begin{array}{l}\text { Trabalhar os conceitos de Afrocentricidade e Eurocentrismo. Incentivar } \\
\text { e mediar investigação da influência kemética na construção da } \\
\text { cultura grega. } \\
\text { Pensar em sequências didáticas que utilizem como principais recursos } \\
\text { textos e filmes de autores africanos, com intuito de fazer os alunos } \\
\text { entenderem que o conhecimento é algo construído e que há versões } \\
\text { e discursos diferentes sobre um mesmo fato histórico. }\end{array}$ \\
\hline
\end{tabular}

Fonte: autora do artigo.

Otero \& Llanos (2019, p.197) defendem que a disseminação das respostas tem um componente fortemente epistêmico, e, estas, nos revelaram, como podemos observar nos quadros 1 e 2, quais bases epistêmicas alicerçam os currículos, os livros didáticos e, consequentemente, suas práticas no chão da sala

18 Conduzidos pela metodologia, os questionamentos, segundo Chevallard (2012), são desenvolvidos a partir de uma pergunta $Q$, chamada de geratriz, porque não admite uma resposta imediata. Ou seja, será necessário fazer perguntas derivadas e perceber as respostas adquiridas. $O$ meio didático, processo formativo, não é construído a priori, mas em conjunto com as elaborações de respostas dadas pelas cursistas. Os recursos são incorporados conforme a necessidade e a qualquer momento, desde que sejam validadas pela comunidade de estudo.

19 Disponível: https://www.youtube.com/watch? v=eRF-†VK5L28. Acessado em: 12 de abril de 2019. 
de aula.

Quadro 2: Perguntas e respostas no processo construtivo

\begin{tabular}{|c|c|c|c|}
\hline & $\begin{array}{c}\text { Q2- Das abordagens } \\
\text { descoloniais, o que } \\
\text { desconhecia na área de } \\
\text { conhecimento? }\end{array}$ & $\begin{array}{l}\text { Q3 - Quais lacunas você } \\
\text { identifica sua área de } \\
\text { conhecimento. }\end{array}$ & Q4 - Diante das lacunas, dê sugestão de propostas didáticas? \\
\hline $\begin{array}{l}\text { D. Pereira e } 5 . \\
\text { Santiago } \\
\text { (Biologia } \\
\text { Química) }\end{array}$ & $\begin{array}{l}\text { Não havia feito leituras } \\
\text { anteriores } \\
\text { Descolonização } \\
\text { Epistemológica e Didática. }\end{array}$ & $\begin{array}{l}\text { As influências científicas de } \\
\text { africanos como os egípcios, não } \\
\text { serem reconhecidas como } \\
\text { construção de um povo negro; } \\
\text { A associação do conceito de } \\
\text { raças biológicas para } \\
\text { classificação de etnias } \\
\text { humanas; } \\
\text { A associação de doenças } \\
\text { infectocontagiosas e condiç̃̃es } \\
\text { genéticas comuns em povos de } \\
\text { entias africanas com maldições } \\
\text { de divindades cristãs; } \\
\text { Associação de mulheres e } \\
\text { homens negros com uma } \\
\text { concepção preconceituosa } \\
\text { desses seres humanos como } \\
\text { uma subespécie inferior } \\
\text { intelectualmente aos sujeitos } \\
\text { brancos. }\end{array}$ & $\begin{array}{l}\text { Sequência didática baseada em uma QSC (questões sócio-científicas) } \\
\text { com a proposta alinhando o conhecimento teórico com o prático de } \\
\text { maneira contextualizada a fim de potencializar a aprendizagem sobre } \\
\text { o tema proposto e minimizar as visões distorcidas e preconceituosas } \\
\text { que os aprendizes possam trazer, resinificando sua aprendizagem e } \\
\text { contribuindo para a construção de um ensino de Ciências Biológicas } \\
\text { livre de barreiras preconceituosas e discriminatórias. }\end{array}$ \\
\hline $\begin{array}{l}\text { C; José e P. } \\
\text { Santos } \\
\text { (Matemática e } \\
\text { Física) }\end{array}$ & $\begin{array}{l}\text { Afrocentricidade e verdades } \\
\text { epistêmicas. }\end{array}$ & $\begin{array}{l}\text { Verdade lógica versus verdade } \\
\text { do mundo real; } \\
\text { Saberes atemporais universais } \\
\text { versus saberes temporais locais; } \\
\text { O didático e o teórico } \\
\text { desinteressa a realidade; } \\
\text { O conhecimento matemático } \\
\text { enquanto práxis na } \\
\text { globalizacão etnicorracial. }\end{array}$ & $\begin{array}{l}\text { Miniprojetos para "reparar" interpretações e superar interpretações. } \\
\text { Basicamente, pedagogia de projetos. }\end{array}$ \\
\hline
\end{tabular}

Fonte: autora do artigo.

A maioria das docentes denunciaram desconhecer o termo e as perspectivas do paradigma da Afrocentricidade, que, nas entrelinhas, aponta o desconhecimento das histórias do continente africano para além do que promoveu o projeto imperialista europeu, sobretudo, na negação da agência africana e do seu desenvolvimento técnico e tecnológico nas mais diversas áreas das ciências. Declararam o professor de história e a professora de biologia:

[tenho] o desconhecimento de obras de autores africanos, que tragam o ponto de vista daqueles sobre o continente. (professor de História da Rede Estadual da Bahia).

[desconheço] as influências científicas de africanos como os egípcios, [desassociando as influências científicas por ] não serem reconhecidas como construção de um povo negro. (professora de Biologia da Rede Estadual da Bahia).

A dissociação da História Africana e dos corpos negros à História das Ciências (Alves-Brito et al, 2020) evidenciam como o projeto do racismo científico negam qualquer possibilidade de agenciamento positivo do sujeito não-branco tratado e mantido pela colonialidade epistemológica, como denomina Silva (2018, p.144). Assim como foi surpresa do corpo docente sobre o Antigo Egito (Kemet) ser o principal e mais importante referência aos estudos de filósofos gregos como Pitágoras, Tales de Mileto, Platão, Heródoto, dentre outros estudiosos ocidental- 
europeus, será desconhecido pelas suas educandas no chão da sala de aula básica.

Figura 4: Momento de construções com Docentes

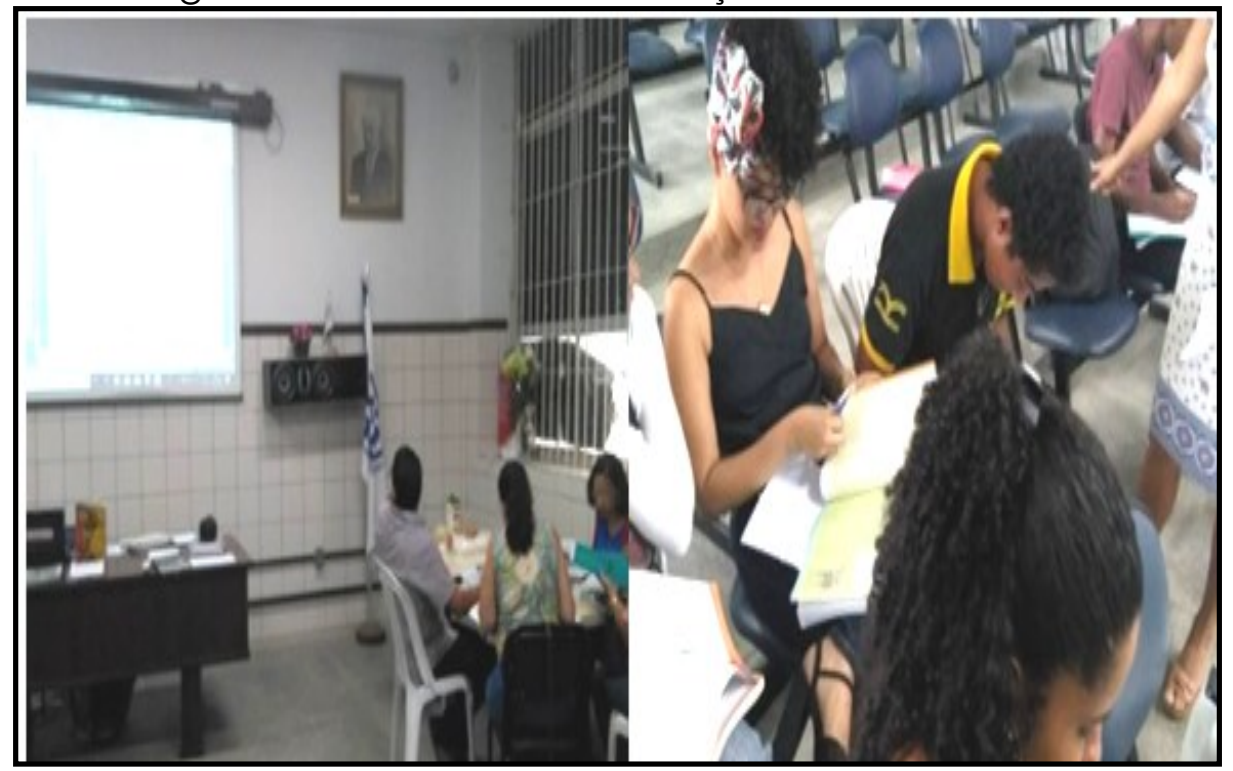

Fonte: NIPEDICMT, 2019.

Assim, a condução foi levada à reflexão, vigilância de comportamento e caminhos à mudança paradigmática no fazer didático proporcionando uma "série de questões sobre os equipamentos praxeológicos necessários aos professores para ensinar de acordo com o novo paradigma" (Otero \& Llanos, 2019). Enquanto um "novo" paradigma às docentes, a Afrocentricidade, como conceitua Mazama (2003), afirma o lugar de sujeito dos africanos dentro de sua própria história e experiências, rejeitando a marginalidade e ausência da alteridade como é expressa pelos os paradigmas europeus, em sua maioria.

Portanto, foi um desafio aos professores essa ruptura paradigmática às suas propostas didáticas. O exercício é contínuo, mas muito ainda apresentaram dificuldades é propor conteúdos etnicorraciais transversais aos conteúdos ditos oficiais, a ideia de 'projeto' como alternativa agregadora e pontual foi muito expressiva, como pode ser visto na proposta de Física e Matemática sugerindo miniprojetos para "reparar" interpretações e superar interpretações.

Assim, promovendo reconstrução, conduzimo-los à realidade de sala de aula, considerando as BNCC (2018) do ensino médio para uma construção efetiva nos seus respectivos conteúdos programáticos. 
Quadro 3: Perguntas e respostas no processo construtivo

\begin{tabular}{|c|c|c|c|}
\hline & $\begin{array}{l}\text { Q- } \frac{\text { Conteúdos da BNCCEM que atrelam às propostas }}{\text { interculturais. }} \\
\text {. }\end{array}$ & $\begin{array}{l}\text { Q- Quais contribuicóes histórico-culfurails- } \\
\text { cientificas afrodiaspórica utilizaria para construção } \\
\text { didática interdisciplinar? }\end{array}$ & Q' sugestão de propostas didáticas? \\
\hline $\begin{array}{r}\text { A. Cerqueira } \\
\text { (História) }\end{array}$ & $\begin{array}{l}\text { Tratar dessas temáticas relacionadas à } \\
\text { história da África, sua produção científica e } \\
\text { tecnológica, em campos como medicina, } \\
\text { astronomia, engenharia, arquitetura, entre } \\
\text { outras áreas, assim como sua influência } \\
\text { cultural na formação de civilizações } \\
\text { sacramentadas pela historiografia como a } \\
\text { grega. }\end{array}$ & $\begin{array}{l}\text { Trabalhar com o tema intelectualidade } \\
\text { negra no império brasileiro, destacando } \\
\text { como antes da abolição da escravidão } \\
\text { no Brasil. }\end{array}$ & $\begin{array}{l}\text { Identificar as trajetórias de vida e contribuições de } \\
\text { alguns membros da intelectualidade negra no } \\
\text { diversos campos do conhecimento e da tecnologia. }\end{array}$ \\
\hline $\begin{array}{l}\text { A, Santos } \\
\text { (Matemática) }\end{array}$ & $\begin{array}{l}\text { Competência específica 1: Utilizar } \\
\text { estratégias, conceitos e procedimentos } \\
\text { matemáticos para interpretar situações em } \\
\text { diversos contextos, sejam atividades } \\
\text { cotidianas, sejam fatos das Ciências da } \\
\text { Natureza e Humanas [...]Competência } \\
\text { específica 2: Articular conhecimentos } \\
\text { matemáticos ao propor e/ou participar de } \\
\text { ações para investigar desafios do mundo } \\
\text { contemporâneo e tomar decisões éticas e } \\
\text { socialmente responsáveis. [..]. }\end{array}$ & Trabalho em equipe & $\begin{array}{l}\text { Tema geral: A África o berço da humanidade } \\
\text { Desenvolvimento 1: Pesquisar a História da África } \\
\text { as contribuições do continente africano para } \\
\text { mundo. } \\
\text { Desenvolvimento } 2 \\
\text { Subtema: Evolução Humana } \\
\text { Subtema: Engenharia no Egito Antigo }\end{array}$ \\
\hline $\begin{array}{l}\text { N. Silveira } \\
\text { (Química) }\end{array}$ & $\begin{array}{l}\text { Matéria e energia - Substância e mistura: } \\
\text { conceito - Classificação de substância: } \\
\text { substância simples e composta. }\end{array}$ & $\begin{array}{l}\text { Geografia, História, Matemática e } \\
\text { Física. }\end{array}$ & $\begin{array}{l}\text { A pesquisa científica pode ser dividida em grupos } \\
\text { por área de atuação e cada área apresentar em forma } \\
\text { de painel, linha do tempo; produção de um vídeo } \\
\text { didático, as suas descobertas e o que pode e deve } \\
\text { estar atrelado ao conhecimento curricular das } \\
\text { disciplinas. }\end{array}$ \\
\hline $\begin{array}{l}\text { P. Santos } \\
\text { (Matemática) }\end{array}$ & $\begin{array}{l}\text { Fenômenos físicos Cinemática e dinâmica } \\
\text { e sua relação com o meio ambiente. }\end{array}$ & Química e Biologia & $\begin{array}{l}\text { Através de um projeto prático ou atividade } \\
\text { construída com uma investigação do processo de } \\
\text { formação da humanidade, de forma que este } \\
\text { surgimento fosse abordado por vários aspectos que } \\
\text { são os conhecimentos de apoios das disciplinas } \\
\text { elencadas. }\end{array}$ \\
\hline $\begin{array}{l}\text { S. Santiago } \\
\text { (Biologia) }\end{array}$ & $\begin{array}{l}\text { Ainda não há um rol de conteúdos } \\
\text { realmente definidos para a área do Ensino } \\
\text { Médio na BNCCEM. O que temos são } \\
\text { eixos temáticos. Dentro deles é que serão } \\
\text { propostos conteúdos a serem trabalhados. } \\
\text { [unducredite que haja possibilidade de } \\
\text { fazer isso mais amplamente quando forem } \\
\text { abordados temas como Surgimento e } \\
\text { evolução da vida e ecologia. }\end{array}$ & Todos professores e componentes. & $\begin{array}{l}\text { Canal de vídeos ou vídeo-aulas que tratasse sobre o } \\
\text { assunto. }\end{array}$ \\
\hline
\end{tabular}

Fonte: autora do artigo.

É possível observar que no processo de reconstrução, as docentes buscaram agregar os conteúdos de maneira mais pontual, correspondendo à instauração de "outros" paradigmas. Os saberes de referências buscam romper com os currículos cristalizados, ainda que estes não apontem caminhos como denunciam o professor de história e a professora de biologia.

O quadro acima nos revela que, mesmo diante das restrições promovidas nos currículos e que se reflete nas sugestões de propostas 20 , as estratégias didáticas

20 No Quadro 3, Q3: Quais contribuições histórico-culturais-científicas afrodiaspórica utilizaria para construção didática interdisciplinar, foi padrão o desvio do que fora solicitado. Esse desvio é esperando, haja vista, desaprender do cânone (RUFINO, 2021) requer exercícios, no fazer, cotidianamente. 
mobilizadas pelo questionamento dos modelos epistemológicos e didáticos referentes possibilitaram aberturas de ecologias (Chevallard, 1999). Os desafios apontaram que a encruzilhada é um caminho estratégico de giro descolonial e, como traz Rufino (2020), os saberes, nas mais diferentes formas, ao se cruzarem, ressaltam as zonas fronteiriças, tempos/espaços de encontros e atravessamentos interculturais que destacam saberes múltiplos e tão vastos e inacabados quanto as experiências humanas.

É nessa caminhada que seguimos entre os desafios e os enfrentamentos para a descolonização didática, considerando ser este, um fenômeno que promove rupturas com as práticas de ensino 'viciadas'. Essas rupturas não se isolam apenas no campo epistêmico, mas, sobretudo, envolve as práxis, ao conduzir à contraposição política e histórica colonial reverberando nas profundas mudanças de comportamentos, de olhares, discursos, de paradigmas, de pensamentos, e, consequentemente, de práticas, tanto individual quanto coletivamente na trama didático-pedagógica.

\section{In-conclusão nos caminhos investigativos}

A presente discussão faz parte de um trabalho investigativo maior que tem nos gerado inquietações e contentamentos pelas mudanças paradigmáticas e comportamentais no percurso. Ressaltamos que, o ponto de chegada deste percurso investigativo é o alcance da descolonização didática, em vista disso, percorro caminhos que se interessam pela produção, pela difusão e pela aprendizagem dos conhecimentos, assim como pelas instituições e atividades que os facilitam ou dificultam.

Se buscamos descolonizar a didática (produção, difusão, aprendizagem, atividades e instituições), subtende-se que estes elementos que compõem a didática são colonizados, determinam uma relação vertical e hierárquica do saber.

Ao longo da discussão apontamos enfrentamentos e desafios que perpassam no promover didático e pedagógico na efetivação do que determinam as leis 10.639/03 e 11.645/08. Para esse momento in-conclusivo, no nosso percurso de estudo e pesquisa, sigamos nas encruzilhadas descolonial para construções justas e equânimes no chão da sala de aula. 
Referência bibliográfica

BRITO, Alan Alves. Astro-antropo-lógicas: oriki das matérias (in)visíveis. Porto Alegre: Marcavisual, 2021.

MACHADO, Aldibênia Freire. Filosofia Africana Para Descolonizar Olhares: Perspectivas para o Ensino das Relações Étnico Raciais. Tear: Revista de Educação Ciência e Tecnologia, Canoas, v.3, n.1, 2014.

SILVA, Nádia Maria Cardoso da. Descolonização Epistêmica na Perspectiva NegroBrasileira. Tese apresentada ao Programa Multidisciplinar de Pós-Graduação em Cultura e Sociedade do Instituto de Humanidades, Artes e Ciências. Salvador, 2018.

SANTOS, Luane Bento dos. Conhecimentos Etnomatemáticos Produzidos por Mulheres Negras Traçadeiras. Revista da ABPN, v. 9, n. 22, mar-jun 2017, p.123-148. NASCIMENTO, Abdias do. O genocídio do negro brasileiro: processo de um racismo mascarado. Universidade de lfé 15 setembro, 1976.

RUFINO, Luiz. Pedagogia das Encruzilhadas. Rio de Janeiro: Morula, 2019.

BRITO, Alan Alves; MASSONI, Neuss Teresinha; GUERRA, Andreia; MACEDO, José Rivair. HISTÓRIAS (IN)VISÍVEIS NAS CIÊNCIAS. I. CHEIKH ANTA DIOP: UM CORPO NEGRO NA FísICA. Revista da ABPN • v. 12, n. 31 • dez 2019 - fev 2020, p. 290-318. DOI 10.31418/2177-2770.2020.

FREIRE, Paulo. Pedagogia do Oprimido. 17ª . Ed. Rio de Janeiro, Paz e Terra, 1987.

KATEMARI, Rosa; BRITO, Alan Alves; PINHEIRO Bárbara Carine Soares. Pós-verdade para quem? Fatos produzidos por uma ciência racista. Caderno Brasileiro de Ensino de Física, v. 37, n. 3, p. 1440-1468, dez. 2020. http://dx.doi.org/10.5007/2175$\underline{7941.2020 v 37 n 3 p 1440}$

COELHO, Mauro Cezar; COELHO, Wilma de Nazaré Baía. As Licenciaturas em Histórias e a Lei 10.639/03 - Percursos de Formação para o Trato com a Diferença? - Educação em Revista. 2018; 34:e192224. DOl: http://dx.doi.org/10.1590/01024698192224

JUNIOR, José Vieira. Rumo a uma nova epistemologia na educação matemática. CERME (4) 2005 - ISBN 84-61 1-3282-3.

HOOKS, Bell. Ensinando a transgredir: a educação como prática da liberdade. São Paulo, Editora WMF Martins Fontes, 2013.

OTERO, Rita Maria; LLANOS, Viviana Carolina. Formación de Profesores de Matemática en Servicio: La Organización de una Enseñanza Basada en Preguntas. $\begin{array}{llllll}\text { REDIMAT, } & \text { Vol. } 8 \text { No. } 2 & 2 & \text { June } 2019 & \text { pp. }\end{array}$ http://dx.doi.org/10.4471/redimat.2019.3618

Chevallard, Yves. Ensino de matemática na sociedade de amanhã: um caso para um contra-paradigma que se aproxima. $12^{\circ}$ Congresso Internacional de Educação Matemática, Seul, Coréia, 2012. 
LIGEIRO, Isabela Rodrigues; BRITO, José Eustáquio de. Formação Docente para as relações étnico- raciais: o que dizem professores de sociologia do ensino médio? Form. Doc., Belo Horizonte, v. 13, n. 27, p. 11-26, mai./ago. https://doi.org/10.31639/rbpfp.v13i27.476

GOMES, Nilma Lino. Educação, identidade negra e formação de professores/as: um olhar sobre o corpo negro e o cabelo crespo. Em Foco: Desigualdades raciais na escola, Educ. Pesqui. 29 (1), Jun 2003.39 